\title{
Balloon dilatation of the aortic valve after previous surgical valvotomy: immediate and follow up results
}

Narayanswami Sreeram, Denise Kitchiner, David Williams, Mark Jackson

\begin{abstract}
Objective-To evaluate the immediate and long-term results of transcatheter balloon dilatation of the aortic valve for restenosis after previous surgical valvo-
\end{abstract} tomy.

Design-Prospective follow up by clinical examination and cross sectional Doppler echocardiography of all patients fulfilling the above criteria.

Setting-Tertiary paediatric cardiology referral centre.

Patients and methods-22 patients (18 male, 4 female)-median (range) age $157 \cdot 5$ (12-254) months-underwent 25 balloon dilatation procedures at a median of 72 (8-155) months after surgery. The median age at surgical valvotomy was $82 \cdot 5(0 \cdot 5-230)$ months and the systolic gradient across the aortic valve immediately after surgery was 31 (0-49) $\mathrm{mm} \mathrm{Hg}$. The indication for dilatation was a Doppler derived peak instantaneous gradient of $>60 \mathrm{~mm} \mathrm{Hg}$ with grade 2 or less aortic regurgitation. A single balloon was used, and the median balloon to annulus ratio was $1(0 \cdot 9-1)$.

Results-After dilatation the catheter pullback gradient decreased acutely from $55(35-75)$ to $30(0-75) \mathrm{mm} \mathrm{Hg}(\mathrm{p}<0 \cdot 01)$ and the Doppler gradient from 74 (52-92) to $40.5(30-96) \mathrm{mm} \mathrm{Hg}(\mathrm{p}<0.01)$. In three patients who underwent a second dilatation of the aortic valve eight months after the first procedure, the pullback gradient decreased from $50(50-60)$ to 15 (15-16) $\mathrm{mm}$ Hg. Aortic regurgitation grade increased from $1(0-2)$ to $2(1-3)$; only one patient had grade 3 regurgitation. Over a median follow up of 33 (2-67) months seven patients had aortic valve replacement for recurrent stenosis (six patients) or severe regurgitation (one patient with grade 3 regurgitation after dilatation, who had partial detachment of one of the valve leaflets). There was no significant difference for the pullback gradient (median of $19 v 32.5 \mathrm{~mm} \mathrm{Hg}$ ), Doppler gradient 24 hours after dilatation (33.5 $v 50.5 \mathrm{~mm} \mathrm{Hg}$; $=0.03)$, or the duration of follow up ( $27.5 v 18$ months) between the 12 patients who did not require further dilatation or surgery and the 10 patients who did.

Conclusions-Balloon dilatation of the aortic valve is a safe and feasible option for palliation of restenosis after surgical valvotomy for congenital aortic valve stenosis. In many patients, however, stenosis progressed and a further intervention was required.

(Br Heart f 1994;71:558-560)

Transcatheter balloon dilatation is an accepted technique for palliation of congenital aortic valve stenosis. ${ }^{1-3}$ There are, however, few reports of the efficacy of the procedure in patients who have undergone a previous surgical valvotomy. ${ }^{4-6}$

Patients and methods

To date, 22 (18 male, 4 female) of 209 patients who had surgical aortic valvotomy over a 20 year period have undergone balloon dilatation for recurrent stenosis. The median (range) age at surgery was $82.5(0 \cdot 5-230)$ months. The valve was bicuspid in 17 , tricuspid in three, and unicommissural in two patients. The median (range) systolic gradient across the valve after surgery was $31(0-49)$ $\mathrm{mm} \mathrm{Hg}$. One patient had undergone a second surgical valvotomy 140 months after the first operation. Patients were selected for balloon dilatation based on a peak instantaneous gradient at follow up Doppler echocardiography of $>60 \mathrm{~mm} \mathrm{Hg}$ (with or without symptoms), and with grade 2 or less regurgitation on colour Doppler ultrasound grading. Informed consent was obtained before all procedures. The median age at balloon dilatation was $157 \cdot 5(12-254)$, months with a median interval from initial surgical valvotomy of 72 (8-155) months.

Balloon dilatation of the aortic valve was performed under general anaesthetic, through a retrograde femoral arterial approach and with a single balloon of appropriate size (median (range) balloon to anulus ratio of 1 $(0 \cdot 9-1)$. Direct pullback gradients were obtained where possible, before and after dilatation. Cardiac output was not routinely measured before and after dilatation, as this has been shown to be largely unaffected by the procedure, in patients with satisfactory left ventricular function. ${ }^{56}$ Also, all patients had cross sectional Doppler echocardiographic estimations of the peak instantaneous gradient, in the awake state, 24 hours before and 24 hours after dilatation. All patients have been followed up by clinical examination and serial cross sectional Doppler echocardiography at subsequent outpatient visits. 


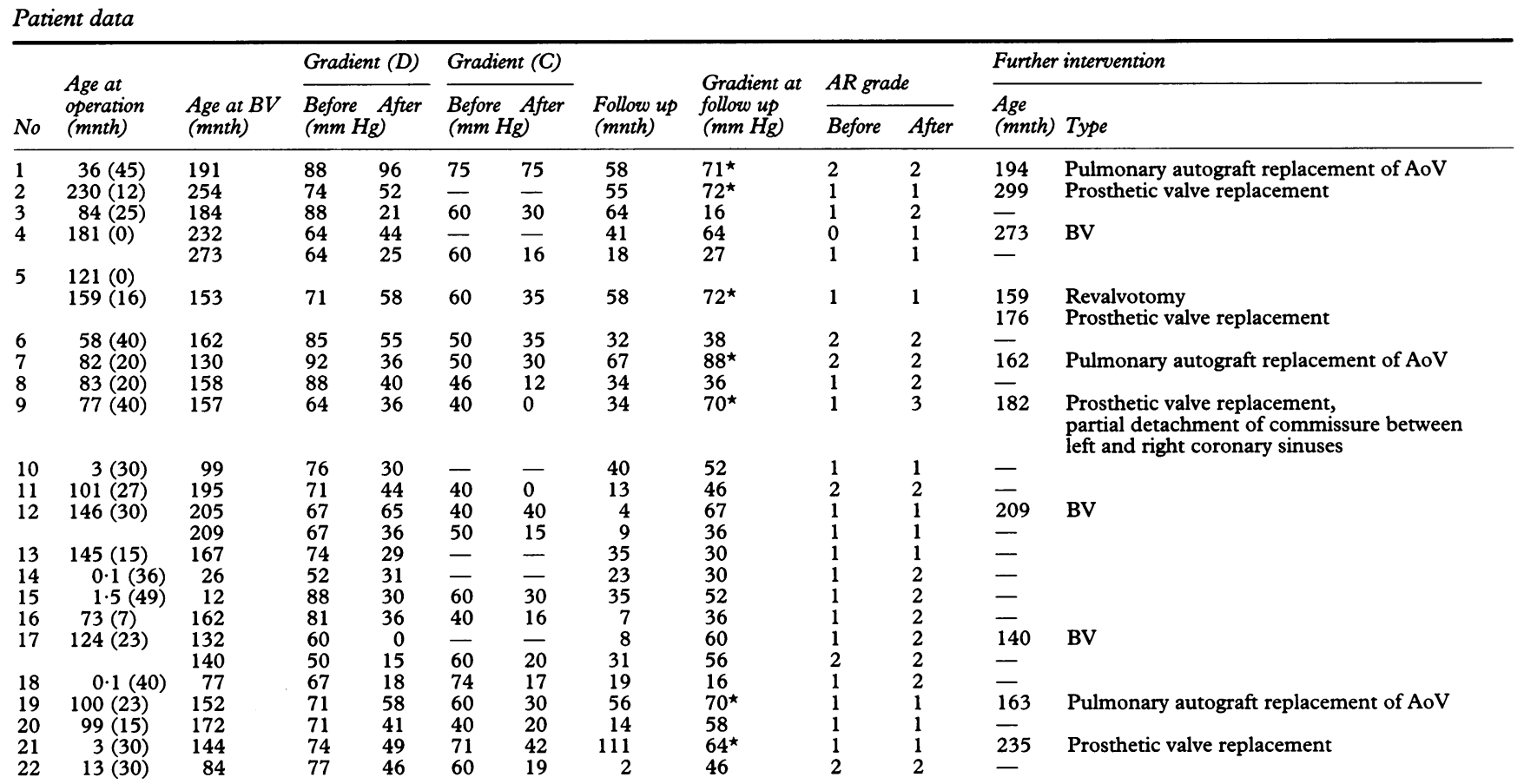

^Follow up gradients recorded just before further surgery. AR, aortic regurgitation; AoV, aortic valve; BV, balloon dilatation of the aortic valve; C, catheter pullback gradient; D, Doppler gradient; numbers in parentheses in column 2 refer to the gradient recorded at completion of surgery.

STATISTICAL METHODS

Because many of the variables investigated were not normally distributed all continuous data are presented as median (range) for consistency. The Wilcoxon sign rank test or the Mann-Whitney $U$ test was used as appropriate. Probability values $\leqslant 0.05$ were regarded as significant.

\section{Results}

Balloon dilatation of the aortic value resulted in a reduction in the catheter withdrawal gradient from 55 (35-75) $\mathrm{mm} \mathrm{Hg}$ to $30(0-75)$ $\mathrm{mm} \mathrm{Hg} ; \mathrm{p}<0.01$ (median percentage reduction in gradient $=50 \%$ ). The Doppler gradient fell from $74(52-92) \mathrm{mm} \mathrm{Hg}$ to $40 \cdot 5$ (30-96) $\mathrm{mm} \mathrm{Hg}$; $<0.01$ (median percentage reduction in gradient $=41 \cdot 3 \%$ ). The grade of aortic regurgitation immediately after dilatation increased from $1(0-2)$ to $2(1-3) ; \mathrm{p}<$ 0.01 (table). All but one patient had aortic regurgitation before balloon dilatation. Only one patient developed grade 3 aortic regurgitation.

Three patients underwent a second balloon dilatation at eight months (four to 41) after the first procedure, with a reduction in gradient from 60 to 16,50 to 15 , and 50 to $15 \mathrm{~mm} \mathrm{Hg}$.

Over a median follow up of 33 (2-67) months after first dilatation, seven patients have undergone surgery either for severe recurrent stenosis (six patients) or for aortic valve regurgitation (one patient with grade 3 regurgitation). The median age at reoperation was 182 (159-299) months, and the interval from balloon dilatation to reoperation was 25 (3-91) months. Reoperation consisted of another valvotomy in one case (followed by valve replacement 17 months later), replacement of the aortic valve with a pulmonary autograft (three patients), or replacement with a mechanical prosthesis (three patients). There were no deaths from reoperation.

The 12 patients who did not require further intervention (balloon dilatation or surgery) had a pullback gradient after dilatation of 19 (0-35) $\mathrm{mm} \mathrm{Hg}$, compared with 32.5 (0-75) $\mathrm{mm} \mathrm{Hg}$ in the 10 patients requiring further dilatation or surgery; $p=0.06$. The respective Doppler gradients 24 hours after dilatation were 33.5 (18-55) $\mathrm{mm} \mathrm{Hg} v 50.5(0-96) \mathrm{mm}$ $\mathrm{Hg} ; \mathrm{p}=0.03$. At follow up, the Doppler gradient across the valve in the 12 patients with a good result was $37(16-58) \mathrm{mm} \mathrm{Hg} v 70$ (50-88) $\mathrm{mm} \mathrm{Hg}$ in the 10 patients needing further intervention; $p<0.001$. There was no significant difference in the duration of follow up between the two groups of patints-a median of $27.5(2-64)$ months in patients with a good result $v 18$ (3-91) months in patients requiring further intervention; $p=$ $0 \cdot 6$. In the only patient with grade 3 regurgitation, surgical inspection showed a detachment for $1 \mathrm{~cm}$ of the commissure between the left and right coronary sinuses along the hinge point. Apart from this case, catheter induced damage to the aortic valve cusps was not noted in any patient undergoing reoperation.

\section{Discussion}

Obstruction may persist or recur after surgical valvotomy, necessitating further intervention. ${ }^{78}$ The results of repeat valvotomy are unsatisfactory $^{8}$ and valve replacement is often required. In a small series Meliones et al reported favourable short and intermediate term results with balloon dilatation of the valve for restenosis after surgical valvotomy. ${ }^{5}$ As the fused commissures of the valve have already been incised, balloon dilatation may 
split the commissures in a more predictable way without tearing or avulsion of the valve leaflets. One main concern is the occurrence of important aortic regurgitation, and the balloon to annulus ratio did not exceed one in any case. Although there was some increase in the grade of regurgitation after dilatation only one patient who developed grade 3 regurgitation needed valve replacement. These results resemble those reported by Witsenburg et al, ${ }^{6}$ where previous surgical valvotomy was not an increased risk factor for development of regurgitation after balloon dilatation. Also, al patients needing valve replacement in their series had at least grade 3 aortic regurgitation after dilatation. ${ }^{6}$ Progression of aortic regurgitation or occurrence of aortic valve prolapse ${ }^{69}$ has not been found in any patient during the relatively long follow up. Neither the catheter withdrawal gradient immediately after dilatation nor the Doppler gradient 24 hours after the procedure was sensitive in differentiating patients with a good result from those needing further intervention. The follow up duration in the two groups was similar, suggesting that progression of disease with time was not the only reason for the poor result after balloon dilatation in some patients. The decision to recommend surgery or further balloon dilatation was an arbitrary one. All three patients in whom a second dilatation was performed remain adequately palliated (table), with a median Doppler gradient of 36 (27 to 56) $\mathrm{mm}$ $\mathrm{Hg}$ at 18 (nine to 31 ) months of follow up.

All follow up gradients (also the decision to perform balloon dilatation or reoperation) have been assessed by Doppler echocardiography. The differences between Doppler derived gradients and catheter pullback gradients have been well described (peak instantaneous gradient $v$ peak to peak withdrawal gradient). The lack of correlation between these measurements may also be in part due to the different conditions of measurement (awake $v$ anaesthetised patients).

In summary, reintervention rates for restenosis after surgical valvotomy are high ( $10 \%$ in this series). Balloon dilatation offers a reasonable alternative palliation in some patients.

1 Lababidi Z, Wu J-R, Walls JT. Percutaneous balloon aortic valvuloplasty: results in 23 patients. Am $\mathcal{F}$ Cardiol 1984; 53:194-7.

2 Rocchini AP, Beekman RH, Shachar GB, Benson L, Schwartz D, Kan JS. Balloon aortic valvuloplasty: results of the valvuloplasty and angioplasty of congenital anomalies registry. Am F Cardiol 1990;65:784-9.

3 O'Connor BK, Beekman RH, Rocchini AP, Rosenthal A Intermediate-term effectiveness of balloon valvuloplasty for congenital aortic stenosis. A prospective follow-up study. Circulation 1991;84:732-8.

4 Sholler GF, Keane JF, Perry SB, Sanders SP, Lock JE. Balloon dilation of congenital aortic valve stenosis. Results and influence of technical and morphological features on outcome. Circulation 1988;78:351-60.

5 Meliones JN, Beekman RH, Rocchini AP, Lacina SJ Balloon valvuloplasty for recurrent aortic stenosis after surgical valvotomy in childhood: immediate and followsurgical valvotomy in childhood: immediate and

6 up studies. . Am Coll Cardiol 1989;13:1106-10. IME, Hess J. Short- and midterm results of balloon IME, Hess J. Short- and midterm results of balloon valvuloplasty for valvular

7 Hsieh K-S, Keane JF, Nadas AS, Bernhard WF, Castaneda AR. Long-term follow-up of valvotomy before 1968 for congenital aortic stenosis. Am $\mathcal{f}$ Cardiol 1986;58:338-41.

8 Fulton DR, Hougen TJ, Keane JF, Rosenthal AR, Norwood WI, Bernhard WF. Repeat aortic valvotomy in children. Am Heart $\mathcal{F}$ 1983;106:60-3

9 Shaddy RE, Boucek MM, Sturtevant JE, Ruttenberg HD, Orsmond GS. Gradient reduction, aortic valve regurgitation and prolapse after balloon aortic valvuloplasty in 32 consecutive patients with congenital aortic stenosis. $f$ Am Coll Cardiol 1990;16:451-6. 